\title{
Optics and Light Trapping for Tandem Solar Cells on Silicon
}

\author{
Niraj N. Lal, Thomas P. White, and Kylie R. Catchpole
}

\begin{abstract}
The rapid advancement of thin-film photovoltaic (PV) technology increases the real possibility of large-area Si-based tandems reaching $30 \%$ efficiency, although light in these devices must be managed carefully. We identify the optical requirements to reach high efficiencies. Strict conditions are placed on material parasitic absorption and transmission of contacts: Absorption of $20 \%$ of sub-bandgap light leads to the required top-cell efficiencies of $18 \%$ at a bandgap of $1.5 \mathrm{eV}$ to break even and $23 \%$ to reach tandem efficiencies of $30 \%$. Perovskite-silicon tandem cells present the first low-cost devices capable of improving standalone $25 \%$ efficiencies and we quantify the efficiency gains and reduced thickness afforded by wavelength-selective light trapping. An analytical formalism for Lambertian tandem light trapping is introduced, yielding stringent requirements for wavelength selectivity. Applying these principles to a perovskite-based top cell characterized by strong absorption and high luminescence efficiency we show that tandem efficiencies greater than $30 \%$ are possible with a bandgap of $E_{g}=1.55 \mathrm{eV}$ and carrier diffusion lengths less than $100 \mathrm{~nm}$. At an optimal top-cell bandgap of $1.7 \mathrm{eV}$, with diffusion lengths of current vapor-deposited $\mathrm{CH}_{3} \mathrm{NH}_{3} \mathrm{PbI}_{x} \mathrm{Cl}_{1-x}$ perovskites, we show that tandem efficiencies beyond $35 \%$ are achievable with careful light management.
\end{abstract}

Index Terms-Lambertian, light trapping, perovskite, silicon, tandem.

\section{INTRODUCTION}

$\mathbf{S}$ OLAR cells currently generate less than $3 \%$ of global electricity. To increase this percentage, the price per watt-peak of solar cells must continue to fall, requiring reduced production costs or increased cell efficiencies. Silicon solar cells currently account for $86 \%$ of the global photovoltaic (PV) market [1]; leveraging this market share is one of the main motivations for increasing the efficiency of crystalline silicon (c-Si) solar cells. The efficiency record for c-Si cells is unlikely to increase significantly in the foreseeable future due to practical Auger limits [2]. This is the motivation for tandem solar cells based on crystalline silicon. Placing a high-bandgap thin-film solar cell on top of a silicon cell utilizes high-energy photons from the Sun at higher voltages, allowing efficiencies beyond the Shockley-Quiesser one junction limit [3], [4].

Manuscript received June 19, 2014; accepted July 11, 2014. Date of publication September 19, 2014; date of current version October 17, 2014. This work was supported by the Australian Renewable Energy Agency and the Australian Research Council.

The authors are with the Centre for Sustainable Energy Systems, Research School of Engineering, Australian National University, Canberra, A.C.T. 0200, Australia (e-mail: niraj.lal@anu.edu.au; thomas.white@anu.edu.au; kylie.catchpole@anu.edu.au).

Color versions of one or more of the figures in this paper are available online at http://ieeexplore.ieee.org.

Digital Object Identifier 10.1109/JPHOTOV.2014.2342491

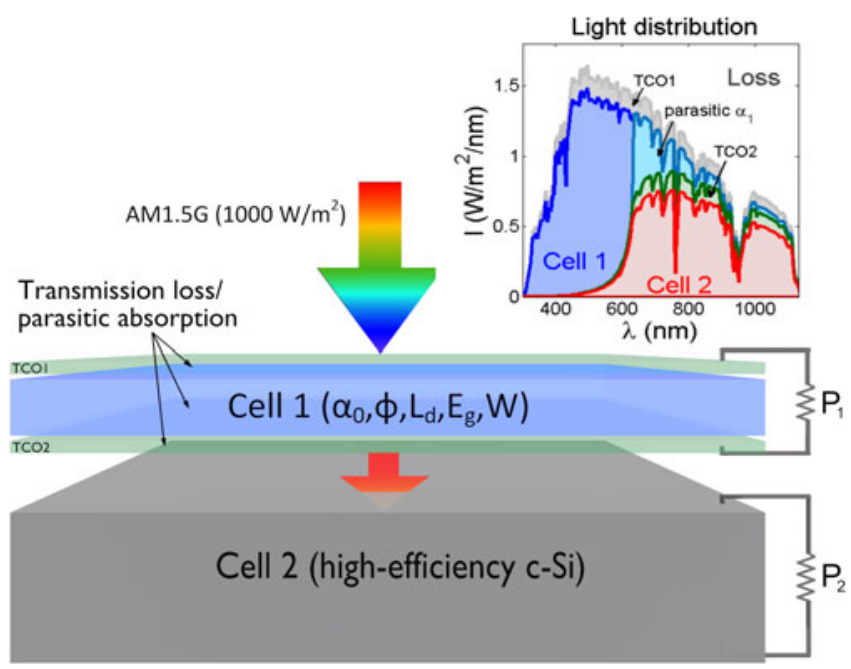

Fig. 1. (a) Schematic representation of a four-terminal tandem cell on silicon. (Inset) Optical distribution of absorbed sunlight (AM1.5G) through the complete tandem structure.

The rapid advancement of thin-film PV technology increases the real possibility of creating large-area c-Si tandems at $30 \%$ efficiency [5]-[7].

Light in tandem cells must be managed carefully; shortwavelength light should be preferentially absorbed in the top cell and long-wavelength light must be transmitted unimpeded to the bottom cell. Here, we quantitatively examine the importance of selectively directing light to each tandem layer and the critical effect of optical losses throughout the device. This paper identifies the strict optical requirements to reach $30 \%$ tandem cell efficiency and is organized into two parts: 1) analysis of required top-cell efficiencies to break-even and the role of parasitic absorption and 2) analysis of light trapping in tandems and an introduction to a new analytical framework for wavelength-selective Lambertian reflectors. Modeling a perovskite-type absorber with high luminescence efficiency $(\phi=0.55)$ [8], we identify the very high $(>35 \%)$ potential tandem power conversion efficiencies for future perovskites with an optimal bandgap of $1.7 \mathrm{eV}$. We additionally present the capability of current $\mathrm{CH}_{3} \mathrm{NH}_{3} \mathrm{PbI}_{x} \mathrm{Cl}_{1-x}$ materials with $E_{g}=1.55 \mathrm{eV}$ and $100-\mathrm{nm}$ solution-processed material diffusion lengths to achieve tandem-on-silicon efficiencies greater than $30 \%$. Aside from further optimization of PV materials, the analysis identifies two challenges for the optics and materials communities:

1) development of transparent conductors suitable for contacting novel top cells with transmission optimized for both the visible and NIR; 


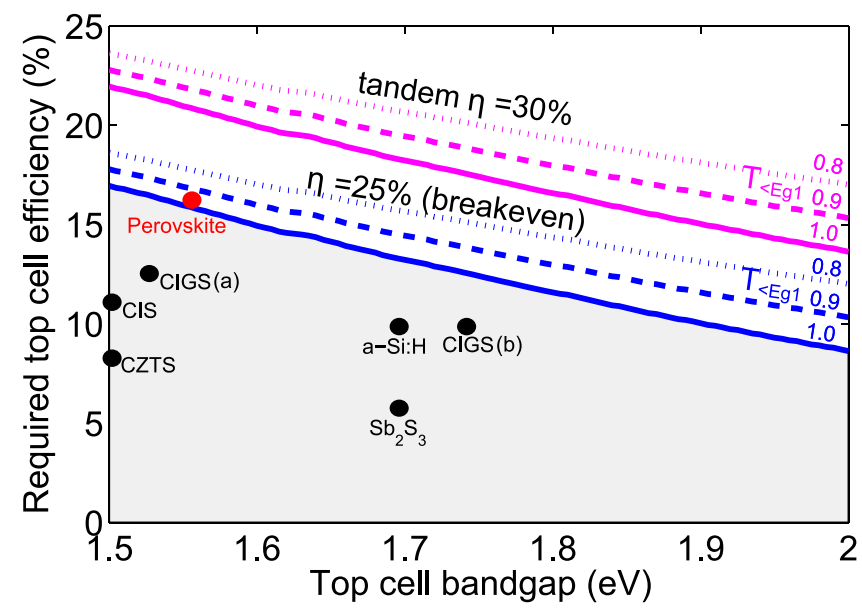

Fig. 2. Required top-cell efficiencies to break-even (blue) and reach $30 \%$ tandem efficiencies (magenta) as a function of top-cell bandgap and sub-bandgap transparencies (dashed lines). The bottom cell is modeled as a PERL cell [7], and record cell efficiencies are for Perovskite [5], CIGS(a) [9], CIS [10], a-Si:H [11], CIGS(b) [12], CZTS [13], and $\mathrm{Sb}_{2} \mathrm{~S}_{3}$ [14].

2) design of materials and structures capable of scattering light selectively, having $<5 \%$ absorption losses and nearperfect transmission for long-wavelength light.

\section{PARASITIC LOSS}

The optical requirements for tandem cells on silicon are strict (see Fig. 1). Short-wavelength light should be absorbed in the top cell; long-wavelength light must transmit unimpeded through the top device to reach the underlying silicon solar cell [15]. As a first approximation, we ignore material details and model the top cell as a filter of short-wavelength light up to its bandgap, reducing the amount of available spectrum for the underlying silicon cell. Using the open-circuit voltage $\left(V_{\text {oc }}\right)$, short-circuit current density $\left(J_{\mathrm{Sc}}\right)$ and fill factor $(\mathrm{FF})$ parameters of the PERL c-Si cell [16], and following the procedure described in [7], we calculate the output power of the silicon cell under the solar illumination it would receive after being filtered by the top cell to its bandgap (see Fig. 2). By taking this output power and subtracting it from the total tandem power required to breakeven (i.e., recover the original $\mathrm{Si}$ cell output of $25 \mathrm{~mW} / \mathrm{cm}^{2}$ ), or reach $30 \%\left(30 \mathrm{~mW} / \mathrm{cm}^{2}\right)$, we can identify the required top-cell power (and, hence, efficiency) to reach a break-even $25 \%$ efficient tandem cell (blue solid line) and a 30\% tandem (magenta solid line) [7]. The solid lines in Fig. 2 assume nothing about the top cell apart from its bandgap; sub-bandgap light is transmitted completely to the underlying silicon cell allowing calculation of the silicon cell power, from which the required top-cell power can be found. Reflection from the top surface is assumed to be negligible.

Light absorbed usefully within the top cell contributes to short-circuit current at higher voltage; nontransmitted light is lost to the whole device. The main sources of this optical loss are contact absorption and material parasitic absorption (identified in the inset of Fig. 1), and the optical loss from light trapping is discussed further in Section III.

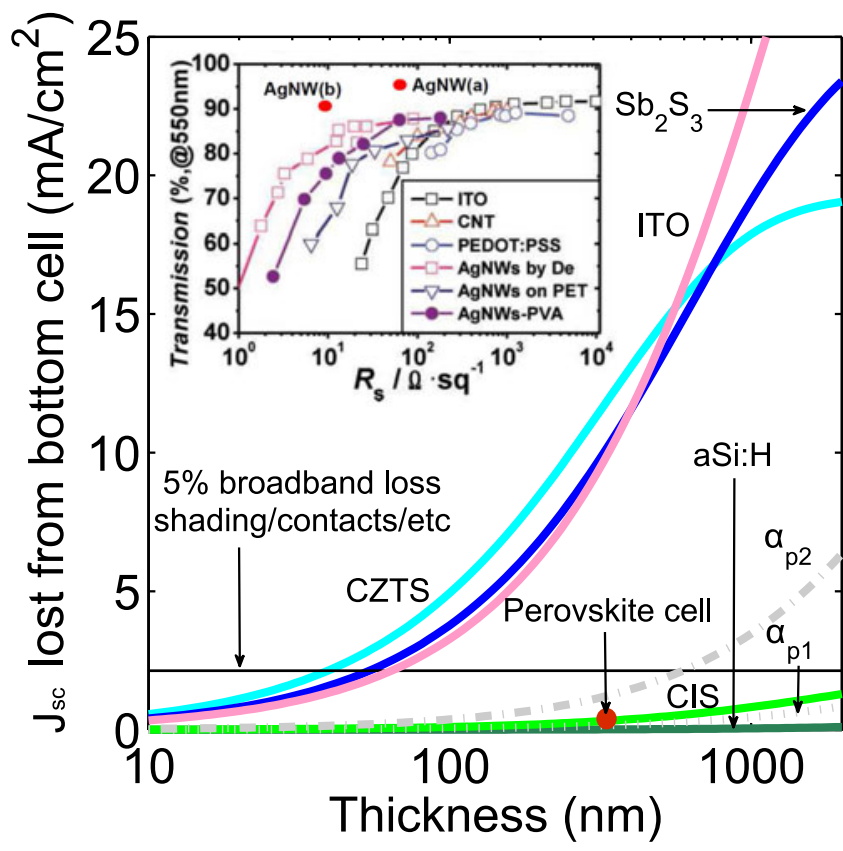

Fig. 3. $J_{\mathrm{sc}}$ lost from the bottom cell as a function of thickness. (Inset) Transmission versus sheet resistance for candidate transparent conductors from [18], additional AgNW points from [19]. Absorption data are taken from the following for CZTS [20], ITO $\left(R_{s} \sim 200 \Omega / \square\right)$ [21], a-Si:H [22], CIS [23], and Perovskite [6].

Tandem-on-silicon devices will employ at least one transparent electrode. Depending on the cell configuration, the rear electrode may either be shared with the $\mathrm{Si}$ cell or comprise an additional transparent contacting material. Each case must ensure near unity transmission of sub-bandgap light.

We can examine the effect of imperfect transmission by multiplying sub-bandgap light by 0.9 and 0.8 to model $10 \%$ and $20 \%$ broadband parasitic absorption, respectively (dashed lines). Each 10\% reduction in transmission of sub-bandgap light raises the required top-cell efficiency by approximately $1 \%$ absolute. The markers in Fig. 2 indicate the record efficiencies of candidate low-cost top-cell materials positioned at their respective material bandgaps. Recent progress with perovskites demonstrates the first ever thin-film low-cost cells with the potential to reach the $25 \%$ tandem break-even point, with further gains in efficiency expected in the immediate future. This is especially remarkable considering the rapid progress from less than $2 \%$ efficiency in five years [17]. No other low-cost top cell currently has the efficiency to potentially improve on the $25 \%$ efficiency of an excellent c-Si solar cell-other candidate materials fall well below the break-even point. While a PERL cell was used for modeling, results are similar for any $>24 \%$ high-efficiency c-Si cell. The solid lines in Fig. 2 assume complete transparency of sub-bandgap light, but it is important to note that each of the record devices on the graph are currently completely opaque, having full-coverage rear metal contacts.

The standard transparent conducting oxides ITO and FTO typically exhibit less than $90 \%$ transparency at $550 \mathrm{~nm}$ (see the inset of Fig. 3), which is often much lower at wavelengths 
$>700 \mathrm{~nm}$. Silver nanowires, graphene, and wire-metal-oxide hybrids promise future high-transparency low-resistivity contacts, although deposition requirements are not yet applicable to the broad range of potential cells. These novel approaches still lead to $\sim 5 \%$ parasitic absorption. Future contacting regimes should include transparent conductors optimized for the visible and NIR at the front of the cell, and NIR at the rear, while each retaining high-conductivity.

Additional loss of useful light arises from parasitic material absorption within the top cell. In Fig. 3, the short-circuit current $\left(J_{\mathrm{sc}}\right)$ lost from the silicon cell is calculated from the integrated parasitic sub-bandgap absorption of various top-cell materials. That is, sub-bandgap light absorbed parasitically in the top cell is summed to calculate the equivalent $J_{\mathrm{sc}}$ denied to the silicon cell. $J_{\mathrm{sc}}$ loss is calculated from published material absorption data $(\alpha(\lambda))$ and the Beer-Lambert Law for all materials except for the perovskite cell, where it is calculated from the difference in absorptance and internal quantum efficiency presented in [6]. $J_{\mathrm{sc}}$ loss from $5 \%$ broadband shading over the full spectrum is included for comparison. Although optical bandgaps and diffusion lengths have been primary considerations for top tandem cell suitability, we highlight here the critical importance of parasitic sub-bandgap absorption as a consideration. While CZTS and perovskite materials have similar bandgaps and diffusion lengths, the $J_{\mathrm{sc}}$ loss due to parasitic sub-bandgap absorption is vastly different, $10 \mathrm{~mA} / \mathrm{cm}^{2}$ at typical cell thicknesses. Similarly, for antimony sulfide and a-Si:H, despite having similar bandgaps, the parasitic absorption of amorphous silicon is negligible, whereas $100 \mathrm{~nm}$ of antimony sulfide denies approximately $5 \mathrm{~mA} / \mathrm{cm}^{2}$ of $J_{\mathrm{sc}}$ to an underlying silicon cell. Amorphous silicon, CIS, and recent perovskite cells show excellent low parasitic absorption due to the sharp cutoff of absorption coefficients at the band edge (see Fig. 9 in the Appendix). This should be a primary consideration of any candidate material for the top cell in a silicon tandem.

\section{LIGHT TRAPPING FOR TANDEMS}

Solar cell thickness is often constrained by diffusion length, morphology, or for mature technologies - material cost. Retaining high optical absorption in thin materials requires light trapping to increase effective optical path lengths. To explore light trapping in tandems with $\mathrm{c}-\mathrm{Si}$, we follow the procedure described in [7] to model a four-terminal tandem cell with a PERL c-Si rear cell [16] and a thin high-bandgap top cell. This top cell is modeled with a future optimal perovskite-based material in mind-using the best-in-class published results to obtain an understanding of what may be attainable with future tandem on c-Si devices. We set the luminescence efficiency of $\phi=0.55$ at 1-sun excitation power from [8] and explore the range of electron-hole diffusion lengths between $L_{d}=110-1100 \mathrm{~nm}$ from [24] and [25]. The cell is modeled with a p-i-n structure, refractive index $n=3$, and direct bandgap absorption with $\alpha=\alpha_{0}\left(\frac{h \nu-E_{g}}{k T}\right)^{\frac{1}{2}}$, where $\alpha_{0}=10^{4} \mathrm{~cm}^{-1}$. The bandgap of the material is set at the optimal two-cell tandem $E_{g 1}=1.7 \mathrm{eV}$ [26]. We later explore tandem efficiencies attainable from current $\mathrm{CH}_{3} \mathrm{NH}_{3} \mathrm{PbI}_{x} \mathrm{Cl}_{1-x}$ materials with $E_{g 1}=1.55 \mathrm{eV}$. Sub-

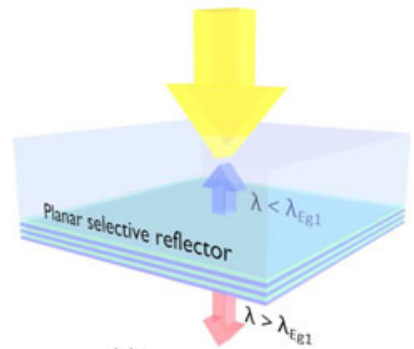

(a)

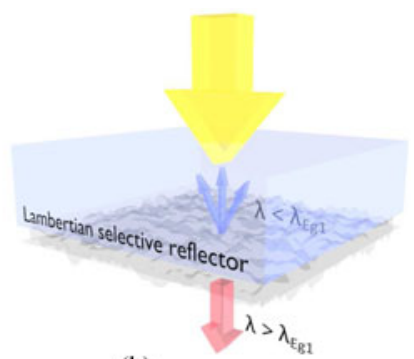

(b)
Fig. 4. Schematic of (a) planar and (b) Lambertian tandem light-trapping methods.

bandgap absorption is modeled at three levels: none $\left(\alpha_{p 0}\right)$, and that based on exponential fits to the parasitic absorption tails of a-Si:H $\left(\alpha_{p 1}\right)$ and antimony sulfide $\left(\alpha_{p 2}\right)$, each being representatives of low and moderate sub-bandgap absorption, respectively (see Fig. 9). $V_{\mathrm{oc}}$ is attained from the bandgap and luminescent efficiency [27], where the intrinsic $V_{\text {oc }}$ of the solar cell equation is reduced by an additional term $\frac{k T}{q} \ln (\phi)$. Carrier collection probability is modeled from [28]. Further details of the model can be found in [7].

\section{A. Intermediate Selective Reflector}

The first and most obvious method of managing light in tandems is to reflect short-wavelength light via an intermediate reflector that remains transparent to sub-bandgap light for the underlying silicon cell [see Fig. 4(a)]. We consider here an intermediate reflector characterized by a step-function reflectance:

$$
R(\lambda)= \begin{cases}R_{\text {int }}, & \lambda \leq \lambda_{E g 1} \\ 0, & \lambda>\lambda_{E g 1}\end{cases}
$$

where the reflector strength can take values $0 \leq R_{\text {int }} \leq 1$.

We first model a perovskite-based absorber with diffusion length $L_{d}=110 \mathrm{~nm}$ as reported for solution-processed cells in [24] to explore the usefulness of light trapping for materials limited in thicknesses due to diffusion length. Analysis of potential tandem efficiencies from materials with $L_{d}=1100 \mathrm{~nm}$ [25] follows below.

Surprisingly, $>30 \%$ efficiencies are found from single-pass absorption of light through the top cell (efficiencies along the $y$-axis in Fig. 5 with $R_{\text {int }}=0$ ). This is due, in part, to the generous p-i-n collection efficiencies of the employed model [28], but also to the high voltages obtained from the top cell with its large luminescence efficiency of $\phi=0.55$ [8]. Counterintuitively, we find that planar selective reflection of short-wavelength light cannot increase the single pass efficiency and is instead always detrimental to total tandem efficiency (see Fig. 5). Increasing $R_{\text {int }}$ ( $x$-axis of Fig. 5) for thin cells strongly reduces tandem efficiency and at best maintains efficiency for top-cell thicknesses optimized for single pass absorption. This is a consequence of unabsorbed reflected light leaving the cell yielding, at most, a $2 \times$ path length enhancement. We find that effective light trapping for tandems must be constructed with more sophistication. 


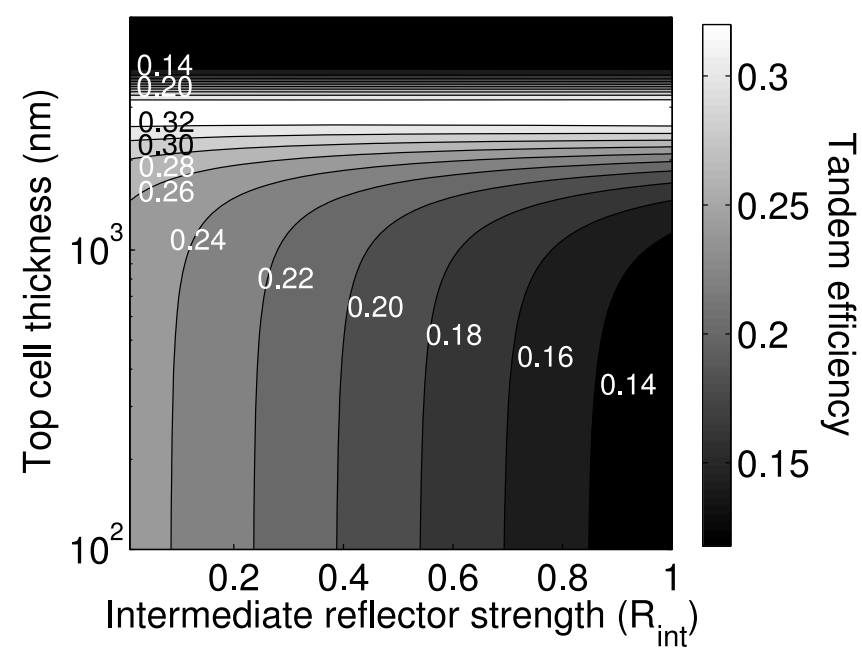

Fig. 5. Tandem efficiency as a function of intermediate reflector strength $\left(R_{\text {int }}\right)$ and top-cell thickness for $L_{d}=100 \mathrm{~nm}$. A planar intermediate reflector is found to be detrimental to tandem efficiency due to maximum $2 \times$ path length enhancement and lost light through the front of the top cell.

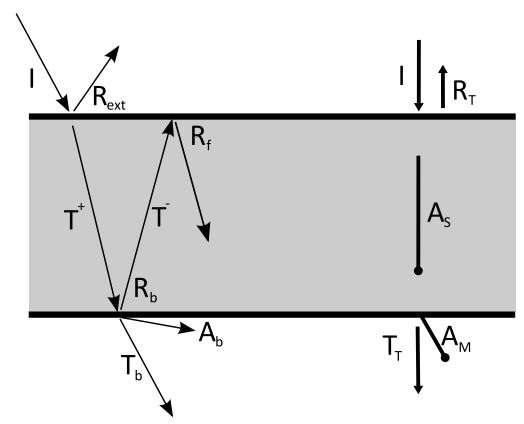

Fig. 6. Schematic representation of optical events (left) and the fate of light (right) for Lambertian light trapping with a selective rear reflector. We introduce the new terms $\mathrm{T}_{\mathrm{b}}$ and $\mathrm{T}_{\mathrm{T}}$.

\section{B. Lambertian Formalism for Tandems}

Analytical equations for broadband Lambertian light trapping in planar films are well established [29], [30] but have previously assumed an opaque rear reflector to provide light trapping - a feature unsuitable for tandem solar cells. We introduce here an extension of this analytical formalism to model light trapping with a selective rear reflector. Following Green's approach [29], we calculate the infinite sum of optical events for a rear reflector randomizing the internal path of light within the absorbing material (see Fig. 6).

We introduce the capability of the rear reflector to transmit light $\left(T_{b}(\lambda)\right)$, in addition to absorbing $\left(A_{b}(\lambda)\right)$ and reflecting $\left(R_{b}(\lambda)\right)$, where $R_{b}(\lambda)+T_{b}(\lambda)+A_{b}(\lambda)=1$. Appropriate choice of the wavelength-dependent terms allows selective Lambertian light trapping of short-wavelength light alongside transmission of long-wavelength light. Summing the infinite series of optical events, we are able to identify the fate of light within the selective Lambertian light-trapping medium with total reflection $\left(R_{T}\right)$, absorption in the semiconductor $\left(A_{S}\right)$, absorption in

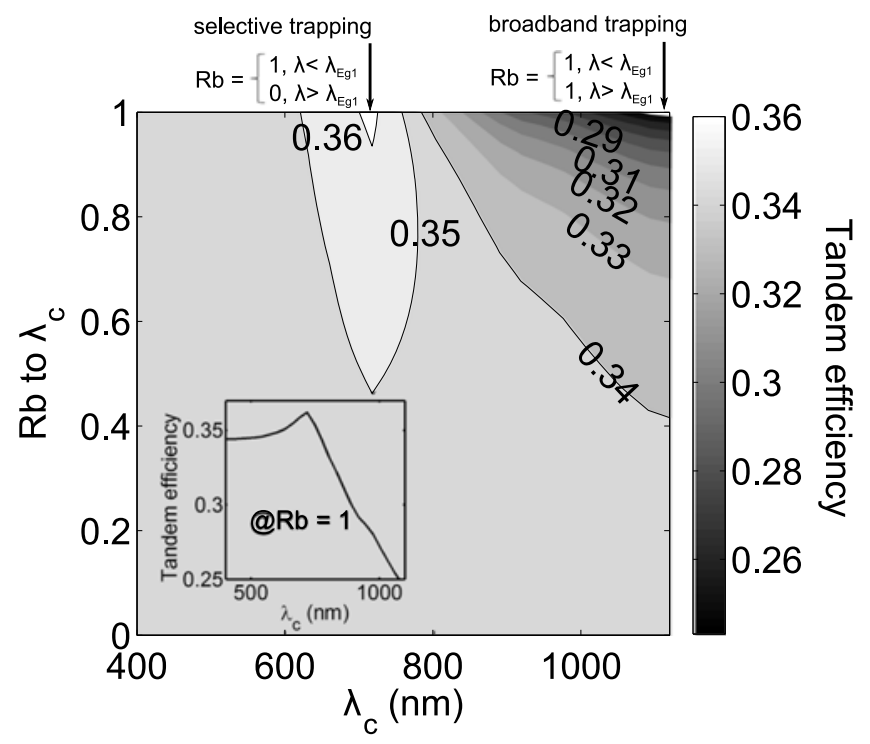

Fig. 7. Efficiency dependence on wavelength selectivity of light trapping for tandems. Contour map of tandem efficiency as a function of rear reflectivity to the cutoff wavelength ( $y$-axis) and the cutoff wavelength ( $x$-axis). Top-cell material bandgap is $\lambda=729 \mathrm{~nm}\left(E g_{1}=1.7 \mathrm{eV}\right)$. Inset showing the line profile for $R_{b}=1$ as a function of $\lambda_{c}$. A peak at the bandgap wavelength is followed by a steep decline for increasingly broadband light trapping.

the "mirror" $\left(A_{M}\right)$, and total transmission $\left(T_{T}\right)$ :

$$
\begin{aligned}
R_{T} & =R_{\mathrm{ext}}+\frac{\left(1-R_{\mathrm{ext}}\right) T^{+} T^{-} R_{b}\left(1-R_{f}\right)}{1-T^{+} T^{-} R_{f} R_{b}} \\
T_{T} & =\frac{\left(1-R_{\mathrm{ext}}\right) T^{+} T_{b}}{1-T^{+} T^{-} R_{f} R_{b}} \\
A_{M} & =\frac{\left(1-R_{\mathrm{ext}}\right) T^{+} A_{b}}{1-T^{+} T^{-} R_{f} R_{b}} \\
A_{S} & =\frac{\left(1-R_{\mathrm{ext}}\right)\left(\left(1-T^{+}\right)+T^{+} R_{b}\left(1-T^{-}\right)\right)}{1-T^{+} T^{-} R_{f} R_{b}} .
\end{aligned}
$$

Using Green's approximate solutions with $a=0.935$ and $b=$ 0.67 for high-refractive-index materials:

$$
\begin{aligned}
R_{\mathrm{ext}} & =0 \\
T^{+}, T^{-} & =e^{-\alpha W_{o p}} \\
W_{o p} & =\left(\frac{2+x}{1+x}\right) \\
x & =a(\alpha W)^{b}
\end{aligned}
$$

we explore the effect of selective Lambertian light trapping for tandem solar cells [see Fig. 4(b)]. Fig. 7 presents tandem efficiency contours as a function of rear Lambertian reflectivity $\left(R_{b}\right.$, $y$-axis) and the cutoff wavelength of the selective rear reflector ( $\lambda_{c}, x$-axis), for the material modeled with a diffusion length of $110 \mathrm{~nm}$. The inset of Fig. 7 presents the efficiency along the top edge of the figure, where $R_{b}=1$. 


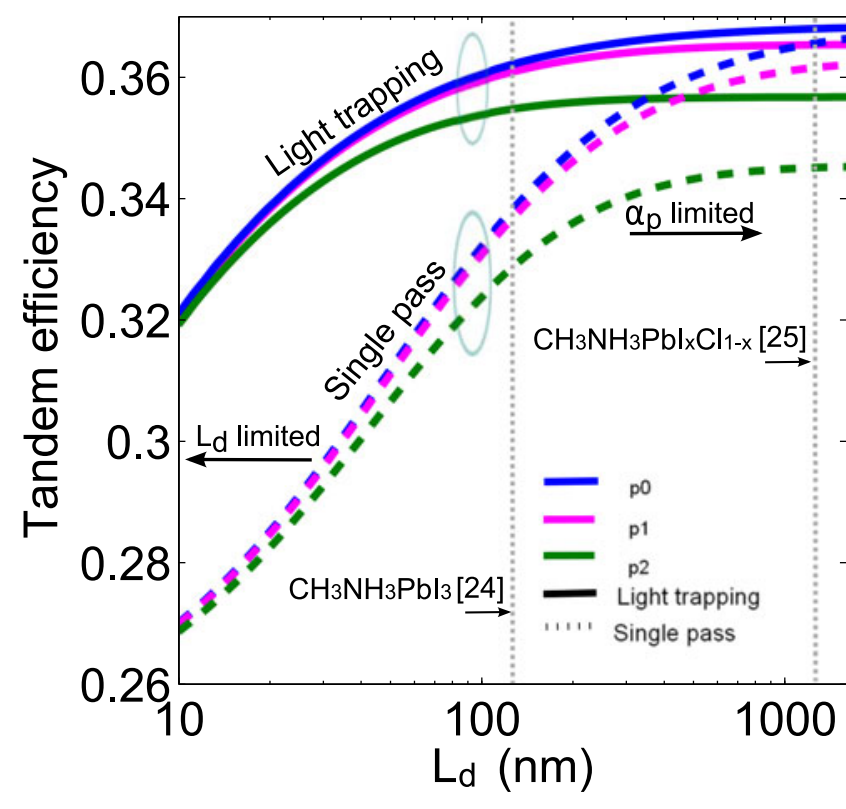

Fig. 8. Tandem efficiency versus diffusion length for top cells with and without Lambertian light trapping for varying degrees of parasitic absorption.

As expected, selective light trapping for wavelengths up to $\lambda_{E g_{1}}$ is optimal for the tandem top cell (i.e., $\lambda_{c}=\lambda_{E g_{1}}$ ), yielding a $2 \%$ absolute increase in tandem efficiency above the optimized single-pass efficiency of $34 \%\left(R_{b}(\lambda)=0\right)$. The efficiency decreases, however, with trapping of light beyond the top-cell bandgap due to reflection loss $\left(R_{T}\right)$ (see the inset of Fig. 7). Unless reduced c-Si current is desirable for current matching in a two-terminal tandem, it is imperative to not trap light beyond the top-cell bandgap; having $R_{b}=1$ at even $100 \mathrm{~nm}$ beyond the bandgap ( $\lambda_{c}=829 \mathrm{~nm}$ ) leads to efficiencies below that of having no light trapping at all (broadband $R_{b}(\lambda)=0$ ). We identify here a key design principle: Broadband light trapping is so detrimental in tandems that unless light can be trapped selectively with low long-wavelength reflectance, the design is best optimized with single-pass absorption $\left(R_{b}(\lambda)=0\right)$. This places restrictions on the type of light-trapping approaches that may be used-plasmonic [31], dielectric [32], or combined methods [33]. Fig. 7 was calculated for zero parasitic absorption in the rear reflector $A_{b}=0$; the effect of increased $A_{b}$ is included in Fig. 10 in the Appendix. We next examine the effect of diffusion length on potential efficiency, alongside the impact of parasitic material absorption and light trapping.

Fig. 8 presents tandem efficiency as a function of top-cell diffusion length for various top-cell sub-bandgap parasitic absorption tails $\left(\alpha_{0,1,2}\right)$, allowing identification of two regimes: top cells with low diffusion lengths require light trapping to increase the optical path length and top cells with large diffusion lengths are instead limited by parasitic absorption. The single-pass case has absorption calculated via the Beer-Lambert law, and light trapping is included as selectively Lambertian for $\lambda<\lambda_{E g 1}$ (see Fig. 12 in the Appendix for optimized thicknesses). Dotted lines represent the highest reported dif- fusion lengths for solution-processed $\mathrm{CH}_{3} \mathrm{NH}_{3} \mathrm{PbI}_{3}$ [24] and vapor-deposited $\mathrm{CH}_{3} \mathrm{NH}_{3} \mathrm{PbI}_{x} \mathrm{Cl}_{1-x}$ [25] films, respectively. The curve of potential efficiency for materials with the current $\mathrm{CH}_{3} \mathrm{NH}_{3} \mathrm{PbI}_{3}$ bandgaps of $E_{g}=1.55 \mathrm{eV}$ are included in Fig. 11 the Appendix. Selective light trapping yields 3\% absolute increase in tandem efficiency over single-pass absorption for $L_{d}$ limited cells and $0.5-1 \%$ absolute increase in cells with large diffusion lengths. As a proportion of the targeted gain beyond silicon standalone efficiencies, these improvements are substantial. Light trapping also offers a reduction in the optimal thickness of the cell layer between a factor of 3 and 5, depending on the diffusion length (see Fig. 12 in the Appendix.). At the relatively large diffusion lengths of vapor-deposited perovskites [25], we expect $0.5 \%$ absolute increase in efficiency and a threefold reduction in cell thickness with selective Lambertian light trapping. At solution-deposited material diffusion lengths, we expect $2.5 \%$ absolute increase in efficiency and twofold reduction in cell thickness.

Several clear design principles are identified for tandem light trapping.

1) Planar intermediate reflection by a selective reflector is detrimental to tandem efficiency due to escaped light. Selective light trapping must direct light outside of the escape cone.

2) Light trapping must select for light $\lambda<\lambda_{E g_{1}}$; it is better to have weaker yet selective trapping than strong optical features that interact with long wavelength light.

3) Light trapping can yield $>2 \%$ absolute increase in tandem efficiency at solution-processed material diffusion lengths, but if a sharp reflection cutoff at the band edge cannot be maintained, it is better to optimize the cell for planar single-pass absorption.

These principles, alongside the identified parasitic loss considerations, set two emerging challenges for the optics and materials communities.

1) Which light-trapping structures can strongly scatter shortwavelength light with $<5 \%$ absorption losses and nearperfect long-wavelength transmission?

2) Which low-loss transparent conductors can contact novel top cells with transmission optimized for the NIR?

The viability of the tandem-cell-on-silicon approach depends in large part on the response to these questions.

\section{CONCLUSION}

We have examined the distribution of light in tandem solar cells based on crystalline silicon. First with simple power calculations and subsequently with detailed device modeling, we identify the optical requirements to reach $30 \%$ efficiency. Perovskite-silicon tandem cells are identified as the first lowcost devices capable of improving standalone $25 \%$ efficiencies, although strict conditions are placed on material parasitic absorption and transmission of contacts. Sub-bandgap absorption in the top-cell structure greater than $20 \%$ leads to required top-cell efficiencies of $18 \%$ at $E g_{1}=1.55 \mathrm{eV}$ to break-even and $23 \%$ to reach total tandem efficiencies of $30 \%$. 
Modeling a perovskite-type absorber with high $(\phi=0.55)$ luminescence efficiency and a range of diffusion lengths between $L_{d}=110-1100 \mathrm{~nm}$, we quantify the efficiency gains made possible through light trapping. The simplest light management scheme for tandem cells-i.e., an intermediate selective planar reflector-is identified to be detrimental to tandem performance due to lost short-wavelength light. The analytical formalism for Lambertian light trapping is extended to include transmission in the rear reflector, allowing the modeling of short-wavelength selective light trapping. Stringent requirements for wavelength selectivity are identified; singlepass absorption is found to be preferable to broadband Lambertian light trapping in the top cell. Selective light trapping yields $3 \%$ absolute increase in tandem efficiency and twofold reduction in thickness over single-pass absorption for $L_{d}$ limited cells and $0.5-1 \%$ absolute increase in efficiency and threefold reduction in thickness for cells with large diffusion lengths.

Applying these principles to a tandem device, we show that tandem efficiencies greater than $30 \%$ are possible with a bandgap of $E_{g}=1.55 \mathrm{eV}$ and carrier diffusion lengths less than $100 \mathrm{~nm}$. At an optimal top-cell bandgap of $1.7 \mathrm{eV}$ with diffusion lengths of current vapor-deposited $\mathrm{CH}_{3} \mathrm{NH}_{3} \mathrm{PbI}_{x} \mathrm{Cl}_{1-x}$ perovskites, we show that tandem-on-silicon efficiencies beyond $35 \%$ are achievable with careful light management.

\section{APPENDIX}

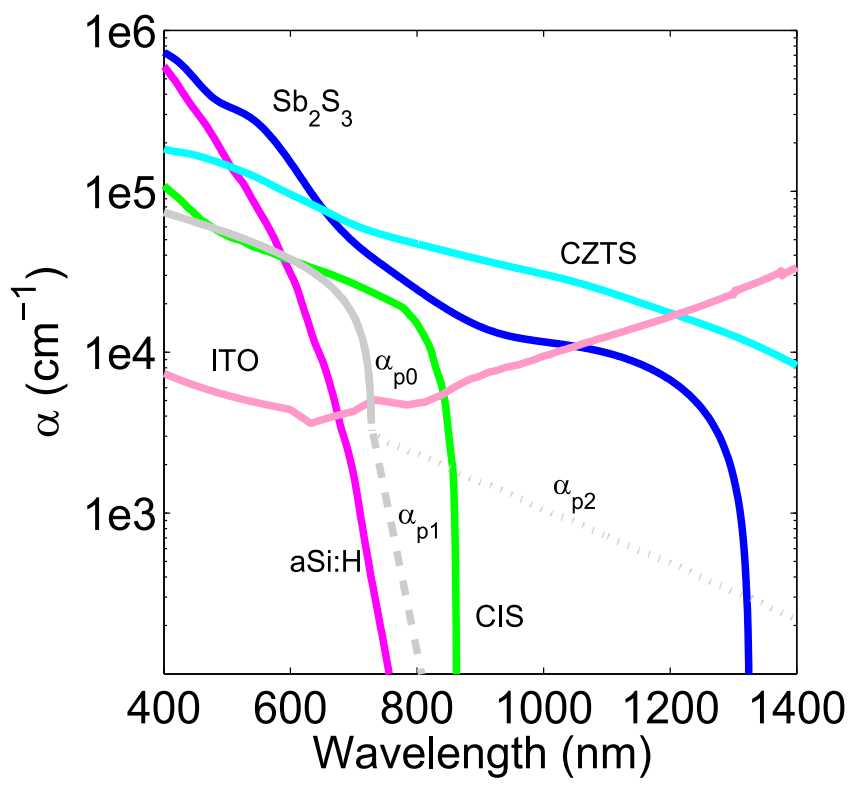

Fig. 9. Absorption coefficient $\left(\alpha \mathrm{cm}^{-1}\right)$ for tandem cell materials. Absorption data are taken from the following for CZTS [20], ITO [21] $\left(R_{s} \sim 200 \Omega / \square\right)$, a-Si:H [22], and CIS [23]. The modeled materials $\alpha_{p 0,1,2}$ are discussed in the main text.

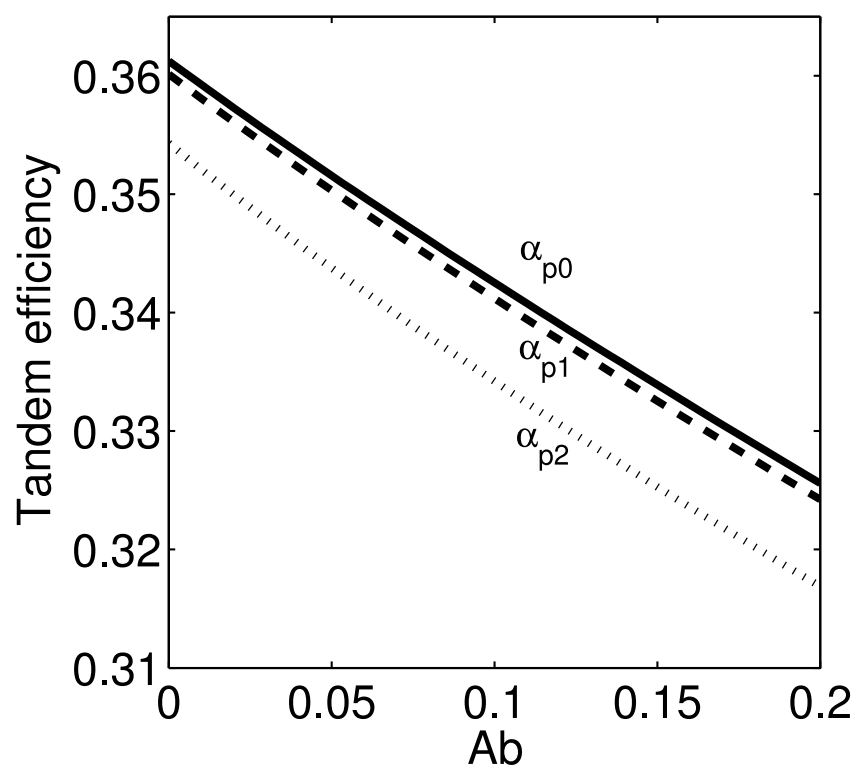

Fig. 10. Maximum tandem efficiency versus absorption in the rear Lambertian reflector $\left(A_{b}\right)$, for varying degrees of parasitic absorption. Approximately $1 \%$ of efficiency is reduced for every $5 \%$ increase in $A_{b}$.

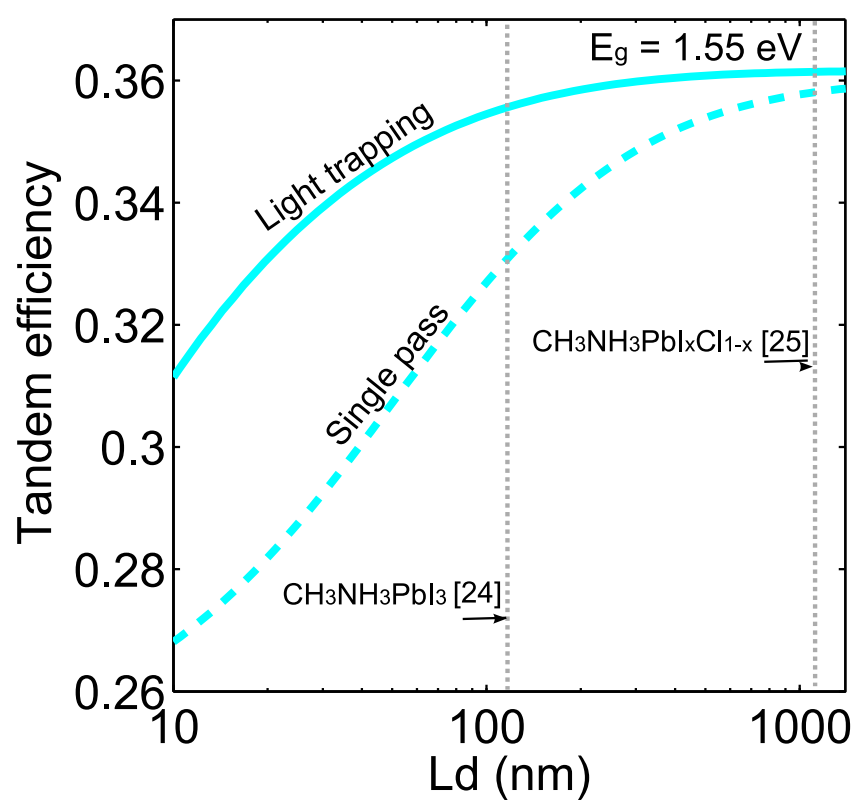

Fig. 11. Tandem efficiency versus diffusion length for a top cell with $E_{g 1}=1.55 \mathrm{eV}$ and no parasitic absorption, with and without Lambertian light trapping. 


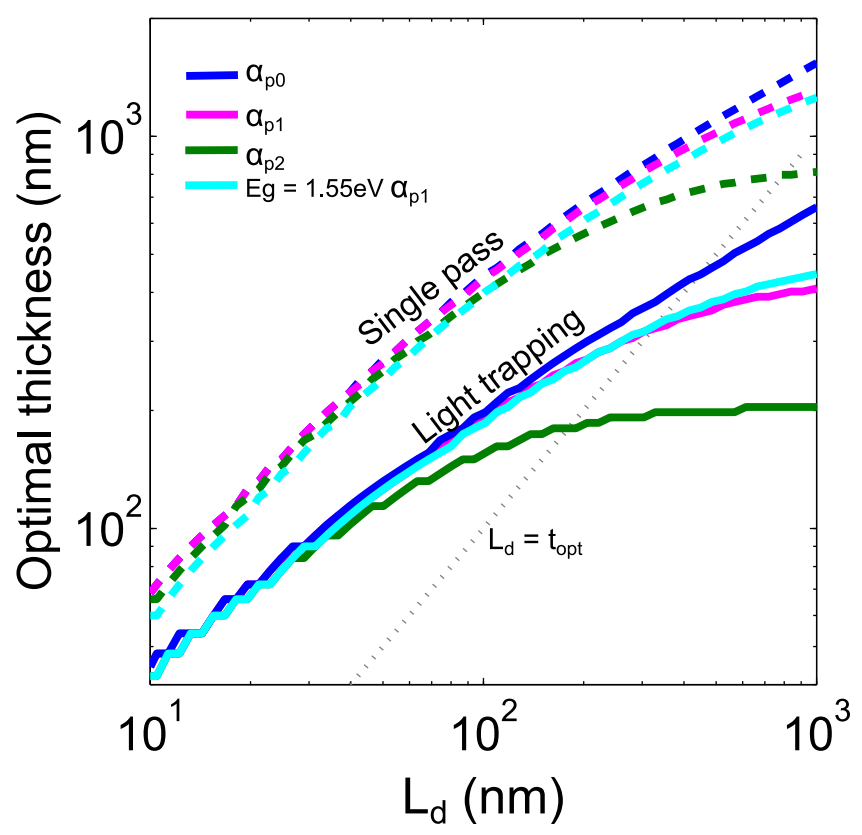

Fig. 12. Optimal thickness as a function of diffusion length for various levels of parasitic absorption, with and without light trapping.

\section{REFERENCES}

[1] R. Schindler and W. Warmuth, Fraunhofer Inst. ISE Annu. Rep., 2013.

[2] M. A. Green, "Limits on the open-circuit voltage and efficiency of silicon solar cells imposed by intrinsic Auger processes," IEEE Trans. Electron. Devices, vol. ED-31, no. 5, pp. 671-678, May 1984.

[3] M. A. Green, Third Generation Photovoltaics: Advanced Solar Energy Conversion. Berlin, Germany: Springer, 2003.

[4] Z. M. Beiley and M. D. McGehee, "Modelling low cost hybrid tandem photovoltaics with the potential for efficiencies exceeding 20\%," Energy Environ. Sci., vol. 5, pp. 9173-9179, 2012.

[5] M. Liu, M. B. Johnston, and H. J. Snaith, "Efficient planar heterojunction perovskite solar cells by vapour deposition," Nature, vol. 501, pp. 395398, 2013.

[6] J. Burschka, N. Pellet, S. Moon, R. Humphry-Baker, P. Gao, M. K. Nazeeruddin, and M. Gratzel, "Sequential deposition as a route to highperformance perovskite-sensitized solar cells," Nature, vol. 499, pp. 316$319,2013$.

[7] T. P. White, N. N. Lal, and K. R. Catchpole, "Tandem solar cells based on high-efficiency c-Si bottom cells: Top cell requirements for $>30 \%$ efficiency," IEEE J. Photovoltaics, vol. 4, no. 1, pp. 208-214, Jan. 2014.

[8] F. Deschler, M. Price, S. Pathak, L. Klintberg, D. D. Jarausch, R. Higler, S. Huettner, T. Leijtens, S. D. Stranks, H. J. Snaith, M. Atature, R. T. Phillips, and R. H. Friend, "High photoluminescence efficiency and optically-pumped lasing in solution-processed mixed halide perovskite semiconductors," J. Phys. Chemistry Lett., vol. 5, pp. 1421-1426, 2014.

[9] S. Merdes, R. Mainz, R. Klenk, M. C. Lux-Steiner, and A. Meeder, " $\mathrm{CdS} / \mathrm{Cu}(\mathrm{In}, \mathrm{Ga}) \mathrm{S}_{2}$ based solar cells with efficiencies reaching $12.9 \%$ prepared by a rapid thermal process," Progress Photovoltaics, Res. Appl., vol. 21, pp. 88-93, 2013.

[10] K. Siemer, J. Klaer, I. Luck, J. Bruns, R. Klenk, and D. Braunig, "Efficient CuInS solar cells from a rapid thermal process (RTP)," Solar Energy Mater. Solar Cells, vol. 67, pp. 159-166, 2001.

[11] S. Benagli, D. Borrello, E. Vallat-Sauvain, J. Meier, U. Kroll, J. Hoetzel, J. Bailat, J. Steinhauser, M. Marmelo, G. Monteduro, and L. Castens, "High-efficiency amorphous silicon devices on LPCVD-ZNO TCO prepared in industrial Kai-M R\&D reactor.," presented at the 24th Eur. Photovoltaic Sol. Energy Conf. Exhib., Hamburg, Germany, Sep. 21-25, 2009.

[12] R. Kaigawa, A. Neisser, R. Klenk, and M. C. Lux-Steiner, "Improved performance of thin film solar cells based on $\mathrm{Cu}(\mathrm{In}, \mathrm{Ga}) \mathrm{S}_{2}$," Thin Solid Films, vol. 415, p. 266, 2002.
[13] B. Shin, O. Gunawan, Y. Zhu, N. A. Bojarczuk, S. J. Chey, and S. Guha, "Thin film solar cell with $8.4 \%$ power conversion efficiency using an earth-abundant $\mathrm{Cu}_{2} \mathrm{ZnSnS}_{4}$ absorber," Progr. Photovoltaics, Res. Appl., vol. 72, pp. 72-76, 2013.

[14] S. H. Im, C Lim, J. A. Chang, Y. H. Lee, N. Maiti, H. Kim, Md. K. Nazeeruddin, M. Gratzel, and S. I. Seok, "Toward interaction of sensitizer and functional moieties in hole-transporting materials for efficient semiconductor-sensitized solar cells," Nano Lett., vol. 11, pp. 4789-4793, 2011.

[15] Z. C. Holman, A. Descoueudres, L. Barraud, and F. Z. Fernandez, "Current losses at the front of silicon heterojunction solar cells," IEEE J. Photovoltaics, vol. 2, no. 1, pp. 7-15, Jan. 2012.

[16] J. Zhao, A. Wang, M. A. Green, and F. Ferrazza, "19.8\% efficient "honeycomb" textured multicrystalline and $24.4 \%$ monocrystalline silicon solar cells," Appl. Phys. Lett., vol. 73, pp. 1991-1993, 1998.

[17] H. J. Snaith, "Perovskites: The emergence of a new era for low-cost, high-efficiency solar cells," J. Phys. Chem. Lett., vol. 4, pp. 3623-3630, 2013

[18] X. Y. Zeng, Q. K. Zhang, R. M. Yu, and C. Z. Lu, "A new transparent conductor: Silver nanowire film buried at the surface of a transparent polymer," Adv. Mater, vol. 22, pp. 4484-4488, 2010.

[19] G. Y. Margulis, M. G. Christoforo, D. Lam, Z. M. Beiley, A. R. Bowring, C. D. Bailie, A. Salleo, and M. D. McGehee, "Spray deposition of silver nanowire electrodes for semitransparent solid-state dye-sensitized solar cells," Adv. Energy Mater., vol. 3, pp. 1657-1663, 2013.

[20] J. Li, H. Du, J. Yarbrough, A. Norman, K. Jones, G. Teeter, F. L. Terry Jr, and D. Levi, "Spectral optical properties of $\mathrm{Cu}_{2} \mathrm{ZnSnS}_{4}$ thin film between 0.73 and 6.5 eV," Opt. Exp., vol. 20, pp. A327-A332, 2012.

[21] R. A. Synowicki, "Spectroscopic ellipsometry characterization of indium tin oxide film microstructure and optical constants," Thin Solid Films, vol. 394, pp. 313-314, 1998.

[22] J. Krc, M. Zeman, F. Smole, and M. Topic, "Optical modeling of a-Si:H solar cells deposited on textured glass $/ \mathrm{SnO}_{2}$ substrates, J. Appl. Phys., vol. 92 , p. 749, 2002.

[23] C. Guillen and J. Herrero, "Optical properties of electrochemically deposited CulnSe $e_{2}$ thin films," Solar Energy Mater., vol. 23, p. 31, 1991.

[24] G. Xing, N. Mathews, S. Sun, S. S. Lim, Y. M. Lam, M. Gratzel, S Mharisalkar, and T. C. Sum, "Long-range balanced electron- and holetransport lengths in organic-inorganic $\mathrm{CH}_{3} \mathrm{NH}_{3} \mathrm{PbI}_{3}$," Science, vol. 342, pp. 344-347, 2013.

[25] S. D. Stranks, G. Eperon, G. Grancini, C. Menelaou, M. J. P. Alcocer, T. Leijtens, L. M. Herz, A. Petrozza, and H. J. Snaith, "Electron-hole diffusion lengths exceeding 1 micrometer in an organometal trihalide perovskite absorber," Science, vol. 342, pp. 341-344, 2013.

[26] F. Meillaud, A. Shah, C. Droz, E. Vallat-Sauvain, and C. Miazza, "Efficiency limits for single-junction and tandem solar cells," Solar Energy Mater. Solar Cells, vol. 90, pp. 2952-2959, 2006.

[27] G. Smestad and H. Ries, "Luminescence and current-voltage characteristics of solar cells and optoelectronic devices," Solar Energy Mater. Solar Cells, vol. 25, pp. 51-71, 1992.

[28] K. Taretto, U. Rau, and J. Werner, "Closed-form expression for the current/voltage characteristics of pin solar cells," Appl. Phys. A: Mater. Sci. Process., vol. 77, p. 865, 2003.

[29] M. A. Green, "Lambertian light trapping in textured solar cells and lightemitting diodes: analytical solutions," Progr. Photovoltaics, Res. Appl., vol. 10, pp. 235-241, 2002.

[30] E. Yablonovitch and G. Cody, "Intensity enhancement in textured optical sheets for solar cells, IEEE Trans. Electron Devices, vol. ED-29, no. 2, pp. 300-305, Feb. 1982.

[31] N. N. Lal, H. Zhou, M. Hawkeye, J. K. Sinha, P. N. Bartlett, G. A. J. Amaratunga, and J. J. Baumberg, "Using spacer layers to control metal and semiconductor absorption in ultrathin solar cells with plasmonic substrates," Phys. Rev. B, vol. 85, p. 245318, 2012.

[32] S. Mokkapati and K. R. Catchpole, "Nanophotonic light trapping in solar cells," J. Appl. Phys., vol. 112, p. 101101, 2012.

[33] A. Polman and H. A. Atwater, "Photonic design principles for ultrahighefficiency photovoltaics," Nature Mater., vol. 11, pp. 174-177, 2012.

Authors' photographs and biographies not available at the time of publication. 